\title{
Physico-chemical changes in Cavendish banana (Musa cavendishii L var Montel) at different positions within a bunch during development and maturation
}

\begin{abstract}
Studies on the physico-chemical changes between different hand positions (top, middle and bottom) within a bunch and different finger positions (upper and lower) within a hand at different maturity stages (between 3 and 15 weeks from the flower emergence) were carried out on 'Montel' banana (Musa cavendishii L). The suitable harvesting stage was found to be between 12 and 15 weeks after flower emergence. The size, weight, volume and peel colour of fruits increased significantly $(\mathrm{P}<0.01)$ for fruits from all positions (hands and fingers within a hand) of the bunch until the end of maturity stage. On the other hand, texture values of the fruit decreased significantly $(\mathrm{P}<0.01)$. The total soluble solids (TSS), ascorbic acid (AA)and sugar contents increased slowly during development, but the increase was rapid during ripening. The starch composition accumulated gradually $(\mathrm{P}<0.05)$ at the early stages and decreased thereafter. The $\mathrm{pH}$ and titratable acidity (TA) values showed an irregular pattern in all the fruits from all positions during the maturity stage. However, significant differences were also detected in size, weight, volume, peel colour, texture, TSS, AA, pH, TA, starch and sugar contents between different hands and different fingers portions from the same bunch.
\end{abstract}

Keyword: Carendish banana; Development; Fingers portion; Hands portion; Maturation; Physico-chemical changes 